\title{
Research for Social Justice: The Narrative for Improving Academic Performance of Learners from Distorted Backgrounds
}

\author{
Vussy A Nkonyane \\ School of Teacher Education, University of South Africa, PO Box 392, UNISA. 0003 \\ Email: nkonyva@unisa.ac.za
}

\section{Doi:10.5901/mjss.2014.v5n20p1854}

\begin{abstract}
There are three problems that have been an albatross on the neck of a free South Africa, inequality, poverty and unemployment. The government calls them the 'triple challenges'. Being conscious of the depth and enormity of the triple challenges, in 2009 the government identified education as first among the priorities to be addressed because it has the potential to help solve the challenges faced by the country. It is believed that if learners can be given a good quality and relevant education, an education where learners are equipped with skills, this can go a long way in addressing the triple challenges. This paper is an attempt at answering the question: how can universities assist in solving the problem of poor academic poor performance by students from disadvantaged backgrounds since they are the ones that train teachers. Tied together with this question is the issue of quality education. Social justice research is used as theory for the grounding of the paper. Suggestions on what needs to be done in response to the situation are made at the end of the paper.
\end{abstract}

Keywords: poor academic performance, social justice research, sustainable learning environments.

\section{Introduction}

It was back on the 30th of December 2009 when my attention was caught by the headlines: "Matrics shine. IEB: 97, 42\% pass of whom 79,5\% qualify for university entry." Since it was December, then this could not be an "April Fool" joke I thought. I struggled to convince myself that I was reading a South African newspaper about South African matric results. A week later, the $8^{\text {th }}$ of January 2010, my confusion was cleared. The headlines of the same newspaper, The Citizen, read: "MATRIC SUICIDE. Failing too much to handle. The lifeless body found hanging from rafters." The dichotomous and conflicting headlines quoted from the same newspaper within a week meticulously captured and represented the problem facing post-apartheid South Africa. To ask who the two above headlines represent is rhetorical. Yet, we cannot avoid asking ourselves questions: why such extreme opposites metaphorically represented by celebration and death in one education system, why are the two groups moving into opposite directions, one almost approaching the point of perfection $(97,42 \%)$ while the other regressing towards the abyss of shambles and mediocrity, does it mean that the super performing groups is naturally imbued with more intelligence than the poorly performing group? A closer look at the two groups and scientific research reveal that it is not their biology of race or intelligence that differentiates between them, but poverty or social class does.

\section{Poverty and Its Effect on Acaademic Achievement}

Poverty as a universal phenomenon is unique in South Africa and elsewhere on the continent because it seems to affect the most majority of the population of the same country while a very small minority enjoys itself in opulence. And at worst, it seems to determine the quality of education that one gets and how far one can be successful in education. Singh explains the impact of poverty on a child well when he says:

The excellent potentialities of the child are destroyed prematurely or are allowed to develop only partially by the adverse socio-economic conditions. Social disadvantage is a deprivation and handicap, the socially disadvantaged child is a trapped one, doomed to stagnation, wastage and failure. Social disadvantage maims and mutilates the child, physically as well as mentally, stunts his growth, destroys his talents and deprives him of self-fulfillment (1980:2).

Education has long been identified as the most important if not a single factor for social development and as such is at the centre of improvement of the lives of millions of poor South Africans. Three of the four points of national developmental vision to 2014 of South Africans are halving unemployment, halving poverty, and improving employment 
equity. In seeking to meet these social and economic aspirations, the government increasingly identified skills developmental as a crucial issue. Skills have thus been seen as both a constraint on socio-competitiveness and the upliftment of those in poverty and those who lack decent work. (Mbeki, $2004 \mathrm{a}$ and b). According to Erasmus and Breier (http://www.hsrc.ac.za) the local trends which have been seen to have influenced skills shortages in South Africa are varied. They include an embattled education system, which is still struggling to overcome decades of dysfunction under apartheid. The various amendments of educational policy on our curriculum, popularly known as Outcome Based Education (OBE) from Curriculum 2005, Revised National Curriculum Statement (RNCS), National Curriculum Statement (NCS) and lately the Curriculum Assessment Policy Statement (CAPS) wherein some of the practices in the curriculum at school level like the teacher's portfolio have been removed by the Minister of Basic Education Angie Motsekga, is an indication that there are concerns and efforts towards improving the efficacy of the education system for quality education for all South Africans. Despite all these efforts, the problem of poor academic performance in public schools seems not only to continue unabated, but exacerbates yearly. This observation is captured well by the Pretoria News headlines of January 8, 2010: "Dismay in fall of pass rate", and from its sister paper the Sowetan of the same date: "What government spin doctors didn't want you to know: 230000 FAILED". It is only in 2014 where we have seen the national pass rate at matric increasing beyond $70 \%$.

Academically the discussion so far can at best be termed as digression. This is unavoidable if the purpose of this paper is to be fulfilled: to declare academic poor performance of public schools in South Africa a national disaster. National disasters are treated with urgency because of the gross damages they cause on the affected communities which are left helpless. This is where institutions of higher education come into play. The following words by Neville Alexander strengthen the call made by this paper:

Every South African citizen who knows that the future of this country depends on the health of the education system has come to realize that at this moment we have no future, this is so because of the fact that they system continues to stagnate and even to regress I crisis mode, in spite of all well-intended interventions by the government and other interested parties (2008).

Honestly, it would be unfair to expect universities to solve the problem of poverty. But this paper believes universities can address the poor performance of learners from distorted backgrounds. Their position and power as knowledge producers in societies put them on a pedestal to directly and successfully face this challenge. The findings of the study: "An analysis of compliance levels with National and Provincial Education legislative and policy imperatives in the Dr Ruth Sekgomotsi Mompati District of the North West Province in South Africa" by Mahlomaholo and Hongwane (2009) indicated that the whole District was firmly located within the poorest of the poor category. According to this study, controlling for 12 schools in the District that did not indicate as to their respective quintile, the remaining 344 schools occured below quintile 3. Only a total of 9 of these schools in the whole District are in quintile 4 and 5. A massive 328 (or $95 \%$ ) of them occur in quintile 3,2 , and 1 . The two researchers noted that even if it can be argued that quintile 3 does not refer to extreme levels of abject poverty, but the remaining number of schools when subtracting those in quintile 3 , is still unacceptably high at $71 \%$ (about 247) of the total. The observation was that all the 4 Area Project Offices (APOs) without exception seem to have an over representation of schools in these low socio-economic status category which may also be a factor in terms of compliance with the policy and legislative imperatives in the schools. Poor matric pass rates in South Africa have consistently occurred in the poor and rural provinces over the two decades. The educational downfall of provinces like Mpumalanga, Eastern Cape and Limpopo can be attributed to the same highlighted findings of the same study.

According to Payne (1996) poverty does not merely stem from a lack of money, but from a deprivation of resources. These resources may include financial, emotional, mental, spiritual, physical, support systems and role models, and/or knowledge of societal rules. And a study by Phipps and Lethbridge (2007) consistently associated higher incomes with better outcomes for children. This study also shows that socioeconomic disadvantage and other risk factors that are associated with poverty (e.g. lower parental education and high family stress) have a negative effect on cognitive development and academic achievement. In most instances poverty does influence children's outlook on life. This observation made social scientists to conclude that what and whom individuals see around them becomes their definition of the norm. The negative impact of poverty on the identity formulation of the child cannot be over-emphasized, hence, in reality, only a few socially disadvantaged children are able to improve their socio-economic status through education. Those who remain in it perform badly. Academic achievement is positively correlated with intelligence, and intelligence is adversely influenced by social disadvantage. With $80 \%$ of public schools classified by experts as dysfunctional, the education system is indeed in deep and chronic crisis. Reacting to this crisis, the government has set itself about five goals to e achieved by 2014:

- A 20\% improvement in key indicators, including improving performance in cross-country tests. 
- Universal access to Grade-R

- Double the number of children aged 0-4 in pre-school

- Increase secondary enrolment to 95\%

- Improve pass rate in post school education by $20 \%$

\section{University and Community Collaborations}

Whether universities should share on the blame for the poor matric results in the country or not is another issue, but they train the teachers at these underperforming public schools and most of what passes on as knowledge to the schools comes from the universities. The present status of our education system's performance demands that higher education institutions cast off their "Ivory tower' image and come down to the 'grassroots' and dirty their hands. This view is supported strongly by Nkonyane (2010) who says:

The community is the minefield of the university in knowledge production since almost all research is carried out in the community. In most cases this information has been used for the benefit of the university by publishing the findings and even fundraising. The same information is not used for the benefit of the communities from whom it is extracted (2010:5).

Adding her voice about the concern on the existing status quo of the question of relationship between university and the community Jean Baxen (2010) asks a few interesting questions:

What kind of knowledge do the universities produce? How is that knowledge used and who benefits from the use of the knowledge? It is clear from the argument on how universities label learners from distorted backgrounds that the poor communities do not benefit from the research that is conducted on and with them by universities.

Baxen (2010) remarks that most of the research carried out in communities is fault finding. It is high time that the university becomes part of the community by sharing in its challenges, failures and successes. By so doing the problems of the community become problems of the university also and in this way the university research will be biased towards finding solutions for the challenges faced by community. This will compel the university to form closer work relationships with communities in establishing strategies how to empower poor schools to improve on the quality of teaching and learning. The learners from disadvantaged backgrounds have negative perceptions about themselves as failures and lacking of the cultural capital of knowledge. The university can assist in changing these perceptions and give them hope on the basis of their resilience through difficulties. One such example is the project "Creating Sustainable Empowering Learning Environments for Social Justice" (SELEN) part of which looks into how underperforming Black schools can be assisted to improve on their performance through partnerships between university and the affected schools. I think it is possible for the university to deal with the "ivory tower" image and make it possible for the learners with poor backgrounds to easily identify with it. This does not suggest the lowering of standards in order to accommodate these learners, but to build bridges between the two institutions and make them accessible to each other through mutual respect and honesty.

\section{Research as an Arsenal for Poor Academic Performance Crisis}

Through research higher education institutions have established archives on poor academic performance by learners from distorted backgrounds. This information has been used by government for policy formulation and has seen the budget expenditure on education increasing yearly in South Africa. Other research has not failed to come up with reasons why and how poor parents contribute towards the poor academic performance of their kids. Almost all research have failed on coming up with suggestions how to address the problem of learners from disadvantaged backgrounds at hand which this paper identifies as a national crisis. This is not surprising if looked from Martin Hammersley's (2003) perspective wherein he critically raises some dilemmas in social research today. Hammersley (2003) points out at the conflict of what research requires versus what policy makers and other users of research want as the first dilemma. Inherent with this dilemma is the tension between the requirements of good research and serving policymakers and various other stakeholders. For funding purposes and keeping their jobs, it is important for researchers to produce good research that will be taken up by policy makers. There is also a moral imperative for practitioner researchers in particular, for inquiry to feed into practice. Yet, at the same time, there are features built into the very nature of research that may limit the extent to which it can be applied to, or translated into practice in any straight forward way (Hammersley, 2003). This dilemma is compounded by the fact that research often has complexities, so that what it presents are not clear-cut and simple findings, but conclusions that are necessarily fallible and to which a range of qualifications must be attached. 
The second dilemma is the relationship between basic versus applied enquiry. The dilemma here is status conflict. In terms of the values of the academy, applied research has often been of low status because it is marginal, in the literal sense that it addresses lay audiences at least as much as academic ones. Furthermore, from this point of view, it is not pure research. It gives other values than truth considerable attention. By contrast, from the perspective of those who emphasize the practical value of knowledge, applied research is often treated as superior to basic research because it has more direct relevance to the current information needs of policy makers and practitioners. The third and last dilemma is the commitment to research versus commitment to social improvement or change (Hammersley, 2003).

For a change this paper suggests that higher education institutions should do qualitative social research: research for social justice. Research for social justice is not of a specific genre, but any research that operates on the principles of John Rawl's social justice theory which provides a framework that explains the significance, in a society assumed to consist of free and equal persons, of political and personal liberties, an equal opportunity, and cooperative arrangements that benefit more the less advantaged members of society. If these principles are not already embraced by society for one or another reason, this research makes overt attempts and work for the realization of such. Qualitative Critical Emancipatory Research (QCER) seems to be more suited for the operationalization and realization of the principles of research for social justice. Among other things, its open subjectivity and biasness towards the disadvantaged, marginalized, and the socially peripheralized, make QCER more qualified for research for social justice. Oliver (1986b) explains the gist of emancipatory research concisely:

The issue for the emancipatory research paradigm is not how to empower people but, how people have decided to empower themselves, precisely what research can do facilitate this process. This does not mean that the social relations of research production do have to change; researchers have to learn how to put their knowledge and skills at the disposal of their research subjects, for them to use (1986a:111).

Ozturk"s (2008) view of education in every sense as one of the fundamental factors of development is very true. No country can achieve substantial economic development without substantial investment in human capital. Education enriches people's understanding of themselves and the world. It improves the quality of their lives and leads to broad social benefits to individuals and society. The fact that the majority South Africans are poor and cannot access and afford the hefty fees of the Independent Examinations Board schools for quality education is an undoing to all other interventions from the government and other organizations. South Africa needs a large pool of diverse skills of labour for it to develop economically, technologically and socially. So far the poor academic performance of the majority learners who are from the distorted backgrounds is an anti-thesis to the vision of a prosperous and peaceful nation. It is in this regard that the paper declares poor academic performance by learners from disadvantaged backgrounds a national crisis or a national injustice which needs urgent attention from all possible stakeholders. Addressing this crisis is vital because it is education that raises people's productivity and creativity and promotes entrepreneurship and technological advancement. In addition, it plays a very crucial role in securing economic and social progress and improving income distribution.

The suggestion of collaboration between universities and communities is borne from the background that universities can use their skills in knowledge production and resources for the benefit of communities, whilst the communities have all the information on what and how to do this process that can eventually benefit everybody. QCER has already been hinted on as offering a suitable frame for such a project. In such research communities and individuals are engaged as agents and not subject of activities, products and knowledge producers; it is research that strives to implement transparent, flexible, and trustworthy processes in communities and between individuals. This research should strive to make the individuals it involves accountable to one another and use systemic research practices and knowledge production to advance an understanding of an issue and its implications for policy, practice, programme delivery, and planning (Minkler \& Wadestein, 2003; Abah, 2007; Levin \& Martin, 2007; Pyrch, 2007). In this research learning is a dialectical interaction between theory, action, lived experience, and critical reflection. QCER can be used as the educational framework that supports this approach to teaching and learning and is mostly common in adult education as it emphasizes more on the learner having control over the learning process and experience (Levin \& Martin, 2007) and this is what de Castell (2004); Ibanez-Carrasso \& Meiners (2004) call; making the curriculum public, making knowledge in public, and making visible the 'rights', agency and reasons for those who produce knowledge (at universities) and those who are left standing on the sidelines.

\section{The Operationalization of Research for Social Justice: A Narrative}

One of the most difficult challenges in doing research for social justice is that it is not about simply identifying a social problem, study its causes and making findings and recommendations as solution to the problem. But, it is based on 
embarking on a journey of the self by the researcher in which she/he carries out a critical analysis of his/her positioning in the social power relations set-up with regards to the researched. This is necessary because it helps the researcher to establish how such a positioning may influence his/her interactions with the researched and what can be done in order to mitigate for the unfair balance of power between the researcher and the researched. There are two important issues that the researcher should always remember he/she carries with him/her when doing research, especially with poor communities; privilege and social power. This should remind the researcher that she/he needs to be extra sensitive on how to handle him/herself within the community where the research is done. This can be achieved through researcher taking up the position of a learner in the research project instead of being a knower as it usually is with researchers. Here research is not done from a diagnostic point of view where researcher comes into the community and tells it what the problem(s) is or are and what the cause and the solutions thereof are. On the collection of data a questionnaire is supplied to the research subjects which they fill in and return to the researcher. Sometimes the researcher does not even show up, but sends sub-ordinates to oversee the data collection process. But research or social justice is research with and for the community and not the other way round where community is research on and treated as subjects. It is research for empowerment from its emancipatory view, which is a struggle in difficult and often hostile contexts with the aim of realizing a view of social justice and the development of the democratic way of life. This view is supported by Roger Simon who argues:

Without a vision of the future pedagogy of empowerment is reduced to a method of participation which takes democracy as an end not a means! There is no moral vision other than the insistence on people having an equal claim in the public arena ... Without something more empowerment becomes an empty and abstract project that is unable to call into question existing contradictions between human capabilities and social forms. It provides us with no guidance as to what forms of knowing and learning might help enhance our chances of developing a just and compassionate society when justice and compassion are so urgently required (1987:375).

Research for social justice advocates for the pedagogy of empowerment because of its capacity to change things for the better for those who have previously been excluded from power. For the intentions of research for social justice to be accomplished, research needs to be politicized. Politicization of research does not mean the use of research for narrow political purpose or because it includes 'politics' as the content or subject of the work, but it is politicized by breaking away from the 'norms' of science: subjectivity, validity, and reliability, instead research intentionally opts for subjectivity and inclusion (Tuhiwai-Smith, 2006). This allows for the research activity to be co-owned by both academia and the communities where it is conducted. In this way inclusion of the different voices, ways of being, multiple truths, and inside perspectives becomes possible (Hodson, 2010). Politicization of research means acknowledging that there is no such a thing as objectivity. We all use our prior constructions of knowledge, skills, understanding and most importantly values and beliefs to comprehend our new experiences or world phenomena. Thus every understanding is subjective and interpretative. Therefore there is no absolute truth. We make our own truths, and as long as they serve us well, they will last. Research for social justice allows for the contestation and negotiation of the constructions of truths from the many different social spaces. This is a research that is openly and intentionally biased towards the marginalized who occupy the periphery of social power and influence. It has the objective of creating and giving space for the voice of the voiceless to be heard (Mahlomaholo, 1998). Research for social justice believes that every human being has a potential in him which if well nurtured, can blossom into fruits that benefit not only the individual, but society as well. When positivistic research emphasizes on how vigorously and rigorously trustworthiness, reliability, and validity as determinants of whether research is scientific or not have been satisfied, research for social justice believes that the same elements are only determined through the success of the research project in empowering the research participants for self-realization, creating hope for the improvement of their lives and giving peace to them (Mahlomaholo, 1998).

\section{Creating Empowering Sustainable Learning Environments for Social Justice}

I was part of the research sub-programme Sustainable Empowering Learning environments for social Justice (SELEN) facilitated and coordinated by Prof. Sechaba Mahlomaholo at the North West University in Potchefstroom. My project in SELEN was: Improving Poor Academic Performance of Learners from Disadvantaged Backgrounds through Creation of Sustainable Empowering Learning Environments. This project originated from my interest in the educational welfare of learners from distorted backgrounds. For this project to take off, I identified one school in the township that was trapped in poor performance at Grade 12 . This school got $48 \%$ matric pass rate in the year 2009. I went through all the necessary formalities of ethics processes when conducting research in any public institution. On my first visit to the school I met the principal from whom I asked what exactly they wanted me to do. He told me the causes of the problem and expected me to come out with some prescriptions in the form of recommendations towards the solution of the problem. I struggled to 
explain to the principal my approach towards research that I am not coming to the school with some solutions to their problem because I am not a knower, but working together with them we can come out with means and ways of addressing the problem at hand. It took me some effort to convince the principal for us to read from the same page on this issue. I explained the framework within which I was operating in my research to him and what it stands for. We set a date where I would meet the whole staff and start with our work. On that day I again introduced Research for Social Justice to the staff to indicate to the teachers that we need to work together as equals in the project for us to reach our goal. Our approach was to put together a strategic plan for the improvement of the school's academic performance. We would achieve that by doing a SWOT (Strength, Weaknesses, Opportunities, Treats) analysis of the school's functioning, especially on teaching and learning activities. The teachers were divided into four groups and each group came out with a well-informed document on each of the elements of the SWOT. Each document was critically analyzed and inputs were made to the satisfaction of everybody. From there the weaknesses, opportunities and threats were tuned into achievable objectives which were listed down and the time limits, responsible people for those objectives and accounting personnel were allocated in a table form. This process took about four and half hours. The final product of the process was a well informed strategic plan which would guide the activities of the school. What was pleasing to the staff was that this plan was not imposed on them but was their own product which they understood all the nitty gritty thereof. I agreed to come after three months to a meeting for feedback on progress and any problems experienced along the way in the implementation of the document.

\section{Conclusion}

It is important to note the centrality of education in the achievement of the national developmental vision 2016 of the government. Education is the feeder belt of the skills which are needed for the socio-economic development of South Africa, and the only point through which the poor people of the country can escape from the misery of poverty. Higher education institutions have a bigger role to play in making this to happen. Research for social justice can be used in the creation of sustainable empowering learning environments where disadvantaged learners can learn successfully even under the conditions of poverty. Such research has as its overt and central intention the restoration of humanity, respect and pride to those whom colonialism, imperialism and oppression have denied. It gives voice to the voiceless and creates space for them to define themselves and tell their own stories. It opens up opportunities for self-empowerment and selfrealization for the downtrodden and structurally peripheralized as they are enabled to shape and determine their own destiny. Poor performance due to poverty is an injustice that cannot be allowed to continue unchallenged; otherwise the political achievements of South Africa since the birth of democracy are built on shaky sands. This problem left unattended to, maybe it might be the cause for future class conflict, who knows?

\section{References}

Baxen, J. (2010). Transforming Institutional Spaces Through Research for Social Justice. Paper presented at EASA conference in Vanderbijl Park: South Africa.

De Castell, S. (2004). Introduction: Private Place in Public Spaces. E. Meniers and F. Ibanez-Carasso (Eds.) Public Art: Disruptive Readings on Curriculum and Research (pp. 135-58) New York. Routledge.

Erasmus and Breier. (2013). http://www.hsrc.ac.z. Accessed on 2013/02/12

Hodson, D. (2010). Time for action: Science education for an alternative future. International Jopurnal of Science Education. Volume 25, Issue 6. Pp. 645- 670.

Nkonyane, V.A. (2010). The University as a Mirror: Identity Construction by Lower-Class Black Learners in Post-Apartheid Higher Education. Paper presented at EASA Conference in Vanderbijl Park: South Africa.

Ibanez-Carasso and Meiners, W. (2004). Hhtp://www.brs.ub.ruhr

Levin, D. and Martin, A. (2007). Education and Development. http://www.jobinformaton exchange.com/arp. Downloaded on 2013/02/17

Mahlomaholo, M. G. (1998). Signification of African Cultural Identity, Individual African Identity and Performance in Mathematics among Some Standard 9 Pupils in Mangaung High Schools. Unpublished D Ed Thesis. University of the Western Cape.

Mahlomaholo, M.G. and Nkonyane, V.A. (2009). District report: An analysis of compliance levels with National and Provincial Education Legislative and Policy Imperatives. North West Province.

Mbeki, T. (2004). State of the Nation Address. South Africa.

Minkler, M. and Waldestein, N. (2003). Community -Based Participation for Health. San Francisco: Josey-Bars.

Neville, A. (2008). http://www/pambazuka.org/en/category/comment/52404

Oliver, M. (1996b). Defining Impairment and Disability: Issues at Stake in C. Barnes and G. Mercer, eds. (1996) Exploring the divide: IIIness and Disability. Leeds: The Disability Press.

Ozturk, I. (2008). The Role of Education in Economic Development: A Theoretical Perspective. http://papers.ssrn.com/sol3/papers.cfm? 
Pretoria News. (2010). "Dismay in fall of pass rate." January 8.

Pyrch, T. (2008). The Role of Education in Economic Development: A Theoretical Perspective. http://www.ucalgary.ca/fsw/faculty

Roger, S. (1987). "The Institute of Public Memory" in Seixas, Pet (Ed.) Theorizing Historical Consciousness. Toronto: University of Toronto Press.

Singh, A.K. (1979). Social disadvantage, intelligence and scholastic achievement, Report of the NCERT Project on Developmental Norms; paper presented at the seminar on Effects on learning of deprivation in early years, NCERT, New Delhi, May 10-12.

Sowetan. 2010. "What government spin doctors didn't want you to know: 230000 FAILED." 8 January.

The Citizen. (2009). "Matrics shine. IEB: 97, 42\% pass of whom 79, 5\% qualify for university entry." 30 December.

The Citizen. (2010). "Matrics shine. IEB: $97,42 \%$ pass of whom $79,5 \%$ qualify for university entry." 8 January.

Tuhiwai-Smith, L. (2006). Decolonizing methodologies: Research and Indigenous Peoples (9th Impression). New Zealand: University of Otago Press. 